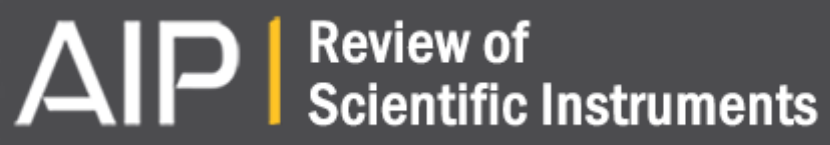

\section{Two Applications of the Sylphon Bellows in High Vacuum Plumbing}

Jesse W. M. DuMond

Citation: Review of Scientific Instruments 6, 285 (1935); doi: 10.1063/1.1752008

View online: http://dx.doi.org/10.1063/1.1752008

View Table of Contents: http://scitation.aip.org/content/aip/journal/rsi/6/9?ver=pdfcov

Published by the AIP Publishing

\section{Articles you may be interested in}

Low Temperature Force Generating Apparatus Using Sylphon Bellows

Rev. Sci. Instrum. 39, 1532 (1968); 10.1063/1.1683156

Bearings for High Vacuum Applications

Rev. Sci. Instrum. 31, 574 (1960); 10.1063/1.1931256

Counterbalanced Bellows in Vacuum Systems

Rev. Sci. Instrum. 27, 1084 (1956); 10.1063/1.1715467

Modified Plumbing Unions for Vacuum Connections

Rev. Sci. Instrum. 24, 984 (1953); 10.1063/1.1770559

Two Aids in High Vacuum Technique

Rev. Sci. Instrum. 8, 130 (1937); 10.1063/1.1752258

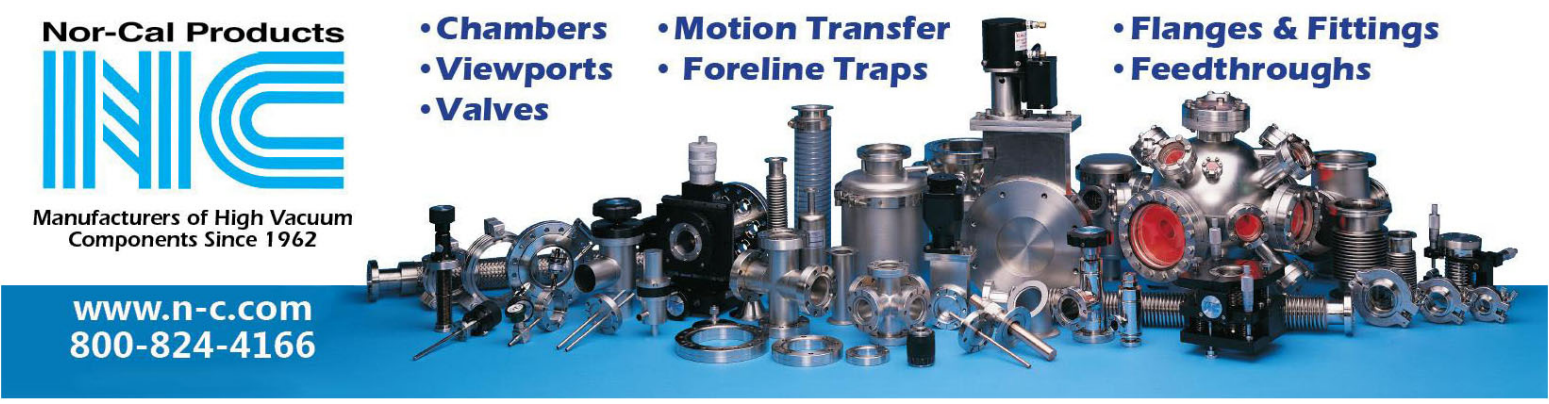



Two Applications of the Sylphon Bellows in High Vacuum
Plumbing

\section{A. A High Vacuum Valve}

The term "vacuum plumbing" is intended to express briefly the mass of technique which has recently been developed by which vacua from $10^{-4}$ to $10^{-6} \mathrm{~mm} \mathrm{Hg}$ or better are obtained in systems mainly of metal and of large volume. The large high voltage $\mathrm{x}$-ray tubes and ion accelerating tubes of C. C. Lauritsen at the California Institute of Technology, E. O. Lawrence at Berkeley and Merle Tuve at the Bureau of Terrestrial Magnetism are three examples of such systems.

It is found extremely convenient to provide valves at various points in such vacuum systems. These permit especially of isolating various parts of a system in testing for leaks and serve many other useful purposes as well. It is highly desirable to eliminate permanently all suspicion of leakage at the valves themselves in order to simplify the work of leak hunting. Joints where no relative motion occurs may readily be made tight in a number of wellknown ways but in a valve the packing gland which is disturbed every time the valve is opened or closed always remains open to suspicion. The valve here described is guaranteed when properly made to be absolutely in a class with Caesar's wife so that the attention of the leak hunter need never be wasted in its direction. Moreover a simple method of testing this valve permits the leak hunter to base his faith in its tightness on a solid experimental foundation.

Figs. $1 A$ and $B$ show a typical $1 \frac{1}{4}$-inch valve before and after installing the sylphon. The valve here shown is a Crane No. 7 but many other makes of valve are doubtless just as readily adaptable. All such valves are very inexpensive. The packing 1 and the sleeve 2 are removed from the valve. The bonnet 3 is centered in the lathe and the depression 4 is turned out with straight cylindrical sides and a flat bottom with a small groove for the lip of the sylphon as shown at 5 . Standard sylphons are obtainable to fit nearly any size valve. For the $1 \frac{1}{4}$-inch valve here pictured the proper sylphon is $1 \frac{5}{8}$-inch O.D. The valve gasket holder 6 comes provided with four prongs 7 which serve to guide it as it rises while the valve is being opened. Chuck the gasket holder in the lathe, turn off these four prongs and finish the
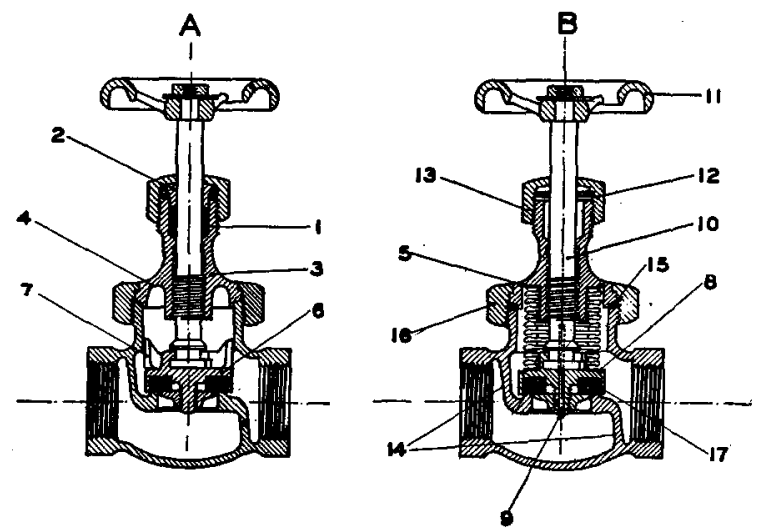

FIG. 1. top surface smooth with another small groove for the other lip of the sylphon as shown at 8 . To secure good alignment and to keep the gasket holder centered in the absence of the prongs drill a $\frac{1}{8}$-inch hole for the pin 9 clear through the gasket holder. The valve stem 10 held in a collet chuck in the lathe is also drilled out for this pin. We always take the precaution to tin the inside surface of the gasket holder against which the gasket fits with soft solder in case the brass may have tiny pores. Tin the grooves and flat surfaces on bonnet and gasket holder before sweating on the sylphon. At the same time the pin 9 is sweated into the hole in the gasket holder. The entire assembly of bonnet, sylphon and gasket holder can now be tested for tightness by removing the hand wheel 11 and the cap 12 and screwing onto the threads 13 a piece of pipe with a standard pipe coupling at the end. For the $1 \frac{1}{4}$-inch valve here shown a $\frac{3}{4}$-inch pipe coupling will be found to fit here exactly. This pipe can thus be connected to compressed air and the bonnet, sylphon and gasket holder immersed under water or painted with soap suds to reveal any leaks in the soldered joints or pores in the castings. We have for our own peace of mind painted the septum 14 with glyptal lacquer on the side toward the atmospheric pressure to remove suspicion of leaks through pores in the casting. We reassemble the bonnet on the valve with a rubber gasket 15 . An endless lead fuse wire gasket could also be used here as the union collar 16 permits of exerting considerable pressure. We use the softest rubber gasket 17 obtainable for this type of valve. After the valve has been assembled in the vacuum line all joints and indeed the whole exterior surface is painted with shellac or glyptal. The shiny painted surface especially near the joints is to be carefully examined during the first service for "suck-ins." We have found valves made in this way to be permanently reliable over long periods of time.

\section{B. A Flexible Noncollapsible Vacuum Coupling}

Fig. 2 shows a simple design of flexible sylphon coupling which we have adopted where glass pumps or glass tubing are to be connected to a rigid metal system to avoid introducing strains into the glass. It has obviously many other applications. The design permits two degrees of flexural

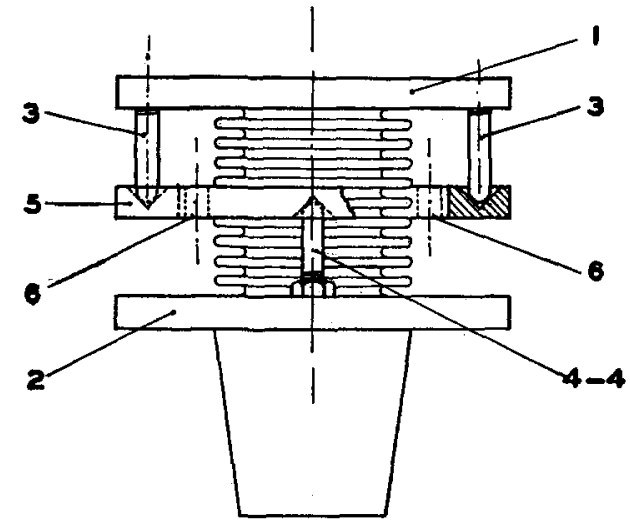

FIG. 2. 


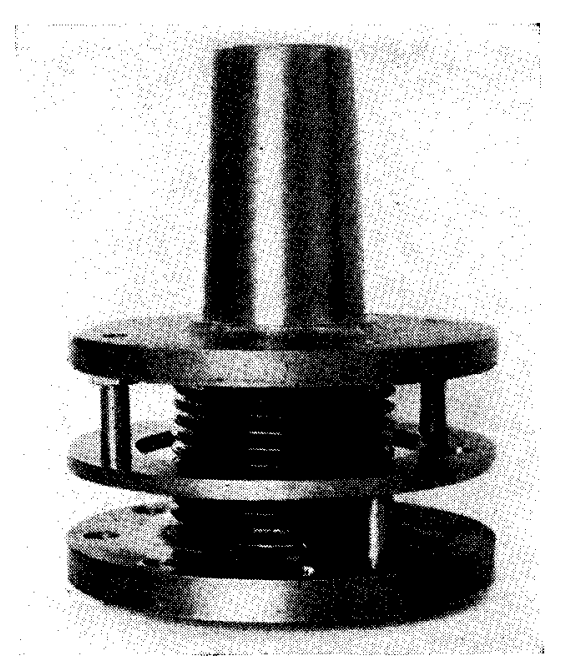

FIG. 3.

freedom and prevents the sylphon from collapsing under atmospheric pressure. Fig. 3 is a photograph of one of these couplings. The sylphon is soldered at either end, Fig. 2, to a flange 1-2 which can be bolted with a gasket or otherwise joined to the rest of the system. One of these flanges is here shown fitted with a taper lapped to fit a glass connection to be made tight with wax. From each flange there projects a pair of columns $3-3,4-4$, the axes of each pair being in a plane through the axis of the system but the planes of the two pairs being mutually at right angles. The rounded ends of these columns fit in conical depressions in the ring 5. To facilitate assembly and soldering the sylphon in place this ring has two diametrically located holes $6-6$ going clear through and of sufficient size to permit slipping the ring down over either pair of the columns to get it out of the way.

California Institute of Technology, Jesse W. M. DuMond

Pasadena, California, July 29, 1935.

\section{A Mifror Optical System to Increase the Resolution of the Moll Microphotometer}

The author has recently had occasion to use the Moll microphotometer under conditions which made it desirable to increase the resolution of the instrument. In the type of instrument used, the light from a strongly illuminated slit is focused on the photographic plate to be measured, and this image is again focused on a thermopile. Resolution may be obtained either at the plate, by making the image of the slit sharp, or at the thermopile, by using a narrow slit

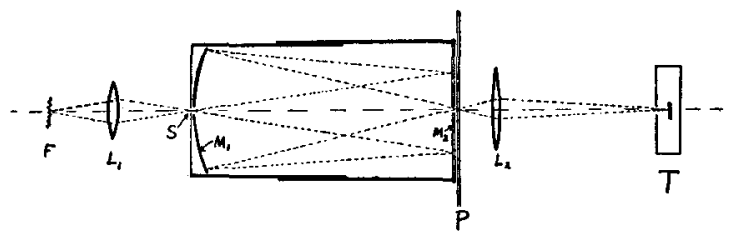

Fig. 1. $F$, lamp filament; $L_{1} L_{2}$, lenses; $S$, slit; $M_{1}$, concave mirror; $M_{2}$, plane mirror; $P$, photographic plate; $T$, thermopile.
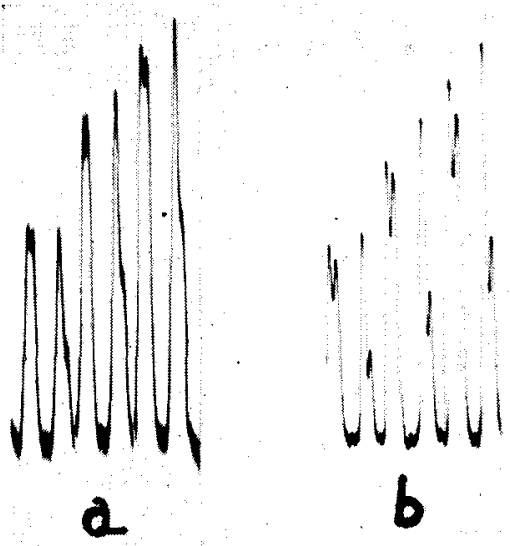

FIG. 2. (a) Trace obtained with lens system. (b) Trace obtained with mirror system.

in the thermopile cover, and focusing the image of the plate sharply upon it. In either case the same difficulty arises in getting a sharp focus. The thermopile is actuated chiefly by near infrared light. Glass lenses ordinarily are not corrected for this region, and consequently will not give a sharp focus over the range of wave-lengths which is effective on the thermopile. It has been found possible to increase the resolution considerably by substituting a mirror system for one of the lenses. The principle of this mirror system was used by Pfund. ${ }^{1}$ Its chief feature is that the image and object lie exactly on the axis of the concave mirror, and thus reduce the aberration to a minimum. Fig. 1 shows how this result is accomplished. The system consists of a plane mirror and a concave mirror, which are mounted coaxially in a telescoping tube. Light from the slit enters the system through a hole in the concave mirror, is reflected by the plane mirror to the concave mirror, and thence through a hole in the plane mirror to the photographic plate.

Fig. 2 shows the increase in resolution obtained with this system. In this figure, traces are shown for the persistent manganese lines at 4030,4033 , and $4034 \mathrm{~A}$, and the potassium lines at 4044 and $4047 \mathrm{~A}$. The manganese lines appear as two lines of nearly equal strength, while the potassium lines show greater difference in intensity. Each group is shown with three different exposures. The two sets of traces were made from the same plate, taken with a medium size Hilger quartz spectrograph (Type E2).

One difficulty which arises with this system is the beam which passes through the holes in the two mirrors without reflection. This was got rid of by tilting the mirrors through a small angle, and lining them up so that this beam did not enter the thermopile case. In order to line up the plate, a small mirror tilted at $45^{\circ}$ could be inserted between the plate and the lens $L_{2}$ and the plate could then be observed through a low power microscope, and placed in the proper position.

Physics Department,

K. B. Thомson

University of Michigan, August 3, 1935.

1 Pfund, J.O.S.A. 14, 337 (1927). 